Check for updates

Cite this: Phys. Chem. Chem. Phys., 2020, 22, 692

Received 3rd September 2019, Accepted 24th October 2019

DOI: 10.1039/c9cp04892h

rsc.li/pccp

\title{
Combined density functional theory and molecular dynamics study of $\mathrm{Sm}_{0.75} \mathrm{~A}_{0.25} \mathrm{Co}_{1-x} \mathrm{Mn}_{x} \mathrm{O}_{2.88}$ $(\mathrm{A}=\mathrm{Ca}, \mathrm{Sr} ; \mathrm{x}=0.125,0.25)$ cathode material for next generation solid oxide fuel cell $\dagger$
}

\author{
Emilia Olsson, (D) ${ }^{a}$ Jonathon Cottom, (D ${ }^{b}$ Xavier Aparicio-Anglès ${ }^{a}$ and \\ Nora H. de Leeuw (iD) *ac
}

\begin{abstract}
One of the main challenges facing solid oxide fuel cell (SOFC) technology is the need to develop materials capable of functioning at intermediate temperatures $\left(500-800{ }^{\circ} \mathrm{C}\right)$, thereby reducing the costs associated with SOFCs. Here, $\mathrm{Sm}_{0.75} \mathrm{~A}_{0.25} \mathrm{Mn}_{x} \mathrm{Co}_{1-x} \mathrm{O}_{2.88}(\mathrm{~A}=\mathrm{Ca}$, or $\mathrm{Sr}$ ) is investigated as a potential new cathode material to substitute the traditional lanthanum-strontium manganate for intermediate temperature SOFCs. Using a combination of density functional theory calculations and molecular dynamics simulations, the crucial parameters for SOFC performance, such as the electronic structure, electronic and ionic conductivity, and thermal expansion coefficient, were evaluated. An evaluation of the results illustrates that the conductivity and thermal match of the materials with the electrolyte is dramatically improved with respect to the existing state-of-the-art.
\end{abstract}

\section{Introduction}

Solid oxide fuel cells (SOFC) are devices that are used to efficiently convert chemical energy into electrical energy. ${ }^{1}$ As the name indicates, the electrolyte material is a solid oxide, in which oxygen anions are driven from the cathode to the anode by means of an oxygen vacancy hopping mechanism. ${ }^{2,3}$ However, high operating temperatures are required in order to ensure maximum oxygen conversion and high oxygen diffusion rates through the materials. These high operating temperatures are known to involve serious drawbacks that directly affect the long-term stability of the device. ${ }^{2,3}$ On the one hand, they favor the reactivity between cell components, and on the other hand, the device is subject to additional mechanical stress derived from the different thermal expansion of the materials. ${ }^{4}$ Hence, the costs of SOFC are inflated due to short cell lifetimes, in addition to the intrinsic high cost of the materials, making improving SOFC durability a key objective before the potential of these devices can be realized. ${ }^{5}$

\footnotetext{
${ }^{a}$ Department of Chemistry, University College London, WC1H OAJ, London, UK

${ }^{b}$ Department of Physics and Astronomy, University College London, WC1E 6BT, London, UK

'School of Chemistry, Cardiff University, Main Building, Park Place, CF10 3AT, Cardiff, UK. E-mail: deLeeuwN@cardiff.ac.uk

$\dagger$ Electronic supplementary information (ESI) available: Interatomic potential set used for the molecular dynamics simulations, the oxygen vacancy compensation scheme equation, dopant configuration selection and Boltzmann distributions, and a graphic description of the cobalt spin state. See DOI: $10.1039 / \mathrm{c} 9 \mathrm{cp} 04892 \mathrm{~h}$
}

Logically, durability can be improved by reducing the energetic budget available to breakdown processes, as such one of the main goals is to reduce the operating temperature. With the current cathode material of choice $\mathrm{La}_{1-x} \mathrm{Sr}_{x} \mathrm{MnO}_{3-d}$ (LSM), the oxygen reduction becomes inefficient and the cathode is no longer able to support efficient oxygen diffusion with a reduced thermal budget. ${ }^{2,6-9}$ As a result, alternative cathode materials have been extensively investigated, among these $\mathrm{SmCoO}_{3}$-based perovskites have gained increasing attention as potential substitutes for LSM. At intermediate temperatures $\left(500-800{ }^{\circ} \mathrm{C}\right)$, $\mathrm{SmCoO}_{3}$-based perovskites have higher oxygen reduction efficiency and, unlike LSM, they support rapid oxygen diffusion, thus showing $\mathrm{SmCoO}_{3}$ to be an efficient mixed ionic and electronic conductor (MIEC). ${ }^{1}$ The balance between both types of conductivity is important, and they are inversely related to the oxygen content. ${ }^{10}$ Hence, high oxygen content benefits electronic conduction $\left(\sigma_{\mathrm{e}}\right)$ but lowers the ionic conductivity $\left(\sigma_{\mathrm{O}}\right)$, consequently leading to lower oxygensurface exchange and high cell polarization resistance. ${ }^{10}$ It is also important to highlight that electronic conduction is typically at least two orders of magnitude larger than the ionic conductivity, therefore, the ionic conductivity is the performance limiting factor for SOFC. ${ }^{10}$ Efficient SOFC cathode materials should also have good oxygen reduction kinetics at the cathode surface, especially efficient $\mathrm{O}_{2}$ dissociation kinetics. Previous work on $\mathrm{O}_{2}$ dissociation on cathode surfaces have shown that this reaction is commonly facilitated by surface oxygen vacancies. ${ }^{11}$

Atomistic level characterization of $\mathrm{SmCoO}_{3}$-based perovskites has remained relatively scarce, and hence systematic study of 
the effect of different dopants on the oxygen diffusion and electronic properties is useful for guiding and understanding experimentally observed trends. Doping $\mathrm{SmCoO}_{3}$ has proven to be an efficient means of balancing both conduction schemes to obtain the best possible performance. From our previous work, we have demonstrated that A-site doping with $\mathrm{Ca}^{2+}$ and $\mathrm{Sr}^{2+}$ significantly enhances oxygen diffusion, ${ }^{12}$ and that B-site doping with $\mathrm{Mn}^{3+}$ allows increasing electronic conductivity $\left(\sigma_{\mathrm{e}}\right)$ and decreasing thermal expansion coefficient (TEC), ${ }^{13}$ improving compatibility with IT-SOFC electrolyte materials such as gadoliniumdoped ceria (GDC). Previous work on related perovskites has shown that the interaction between the divalent dopants and oxygen vacancies (which are formed to charge compensate upon divalent ion doping) can result in the formation of dopantvacancy clusters. These clusters could act as oxygen vacancy traps, hence limiting the ionic conductivity. Ca has generally been seen to have a stronger binding to oxygen vacancies than Sr, but this binding energy is in many cases negligible at IT-SOFC operating conditions. ${ }^{14-17}$ Hence both $\mathrm{Sr}$ and $\mathrm{Ca}$ are investigated as dopants in this study. Furthermore, both $\mathrm{Ca}$ and $\mathrm{Sr}$ are commonly used in La-based perovskites to increase oxygen ion conduction. ${ }^{18,19}$ In this work, we show that the combination of dopants at both the Sm- and Co-sites leads to a cathode material with both high oxygen and electron conduction, guiding the way towards the next generation of cathode materials.

\section{Computational methods}

To investigate the influence of $\mathrm{Ca}, \mathrm{Sr}$, and $\mathrm{Mn}$ doping on the electronic and ionic conductivities, the electronic structure of the different systems was studied using density functional theory (DFT) calculations in the Vienna ab initio simulation package, VASP. ${ }^{20-23}$ The projector-augmented wave method (PAW) was applied to describe the ion-electron interaction, ${ }^{24}$ and the kinetic energy cut-off was set to $500 \mathrm{eV}$. All calculations were spin-polarized with the Perdew-Burke-Ernzerhof $(\mathrm{PBE})^{25}$ functional and ran until electronic and ionic self-consistence, with a convergence criteria of $10^{-5} \mathrm{eV}$ and $10^{-3} \mathrm{eV} \AA^{-1}$, respectively. For each atomic species, we considered the following valence electrons: $\mathrm{Sm}\left(5 \mathrm{~s}^{2} 5 \mathrm{p}^{6} 6 \mathrm{~s}^{2}\right)$, Ca $\left(3 \mathrm{~s}^{2} 3 \mathrm{p}^{6} 4 \mathrm{~s}^{2}\right), \operatorname{Sr}\left(4 \mathrm{~s}^{2} 4 \mathrm{p}^{6} 5 \mathrm{~s}^{2}\right)$, $\operatorname{Mn}\left(3 \mathrm{p}^{6} 3 \mathrm{~d}^{6} 4 \mathrm{~s}^{1}\right)$, Co $\left(4 \mathrm{~s}^{2} 3 \mathrm{~d}^{7}\right)$, and $\mathrm{O}\left(2 \mathrm{~s}^{2} 2 \mathrm{p}^{4}\right)$. The tetrahedron method with Blöchl corrections for smearing ${ }^{26}$ was applied with a $4 \times 4 \times 4 \Gamma$-centered Monkhorst-Pack grid, ${ }^{27}$ and Bader AIM (Atoms in Molecules) charges were calculated using the Henkelman algorithm. ${ }^{28,29}$ All DFT calculations were performed in the 40 atoms $2 \times 2 \times 2 P m \overline{3} m$ pseudo-cubic simulation cell. We have used the On-site coulombic interaction $(\mathrm{DFT}+U)$ for the Co and Mn 3d-electrons to account for the self-interaction error, ${ }^{30-32}$ by means of Dudarev's approach, ${ }^{33}$ with Hubbard parameters ( $U_{\text {eff }}$ ) for Mn and Co of 4 and $3 \mathrm{eV}$ respectively. ${ }^{13,34,35}$ To evaluate $\sigma_{\mathrm{e}}$, the electronic transport properties was calculated using the BoltzTrap code (version 2), ${ }^{36}$ which calculates electronic transport properties in terms of constant relaxation time $(\tau)$ from the Boltzmann transport equation. Due to the lack of experimental data for $\tau$ for the here investigated materials, we present both $\sigma_{\mathrm{e}} / \tau$, and $\sigma_{\mathrm{e}}$ with an approximated $\tau$ from previous literature studies.

In tandem with the DFT $+U$ calculations, molecular dynamics (MD) simulations were conducted to evaluate the ion diffusion and the thermal response of the bulk material, employing the DL_POLY 4.07 code $^{37}$ to simulate a $20 \times 20 \times 20$ supercell (39000 atoms) under NPT conditions with a Nosé-Hoover thermostat. ${ }^{38}$ With a timestep of $0.5 \mathrm{fs}$ and an equilibration period of $11 \mathrm{ps}$, statistics were collected after a production run of 100 ps. The Ewald summation was employed to account for electrostatic interactions, with the Verlet algorithm evaluating the atomic motions. Short-range interatomic interactions were simulated using the Buckingham potential, within the Born model for ionic solids. ${ }^{39-41}$ Electronic polarization was included through the shell model, where ions are modeled as cores with a harmonic spring $(k)$ connected to a massless shell with charge $Y$. The interatomic potentials used here (ESI $\dagger$ Table S1) are primarily obtained from Olsson et al., and Cherry et al., which have previously been used to model ionic conductivity $\left(\sigma_{\mathrm{O}}\right)$ in perovskites. ${ }^{12,19,42-44}$

\section{Results and discussion}

\subsection{Dopant configuration}

To evaluate the effect of the mixed doping scheme on electronic, thermal expansion, and conduction properties of $\mathrm{SmCoO}_{3}$, the energetically most stable dopant configurations need to be explored and identified. To achieve this all the non-equivalent dopant and oxygen vacancy distributions in the $\mathrm{SmCoO}_{3}$ lattice are identified using the Site-Occupancy Disorder (SOD) program. ${ }^{45}$ SOD uses bulk symmetry operations to determine all the inequivalent lattice position, thus limiting consideration of the dopant configurations to the non-equivalent substitutions only. $\mathrm{Sr}$ and $\mathrm{Ca}$ concentrations of 0.25 were considered, based on our previous work. ${ }^{12}$ According to the Kröger-Vink notation for this dopant scheme (ESI $\dagger$ eqn (S.1)), one oxygen vacancy $\left(V_{O}\right)$ is required to ensure the charge neutrality of the system. For Mn, we have considered two different concentrations, 0.125 and 0.25 , based on our previous study on Co-site doping in these materials. ${ }^{13}$ This resulted in 3 different configurations for $x=0.125$, and 23 for $x=0.25$.

After bulk optimization using $\mathrm{DFT}+U$, we calculated the relative abundance of each configuration at intermediate working temperatures using Boltzmann distributions, ${ }^{45}$ showing that only the most stable configuration for each $x$ is expected to be found. This was evident for both concentrations and dopant combinations, although more so for $x=0.125$, where the difference in energy between the different configurations was higher than that found between the three most stable configurations for $x=0.25$ (a full list is available in Table S2 in the ESI $\dagger$ ). Hence, only the most stable configuration per concentration was considered to evaluate the electronic structure of the system.

\subsection{Electronic and magnetic structures}

From projected density of states plots (PDOS), it can be seen that $\mathrm{Sm}_{0.75} \mathrm{~A}_{0.25} \mathrm{Mn}_{x} \mathrm{Co}_{1-x} \mathrm{O}_{2.88}$ is half-metallic with electronic conduction being only possible through the $\alpha$-channel. The effect of 

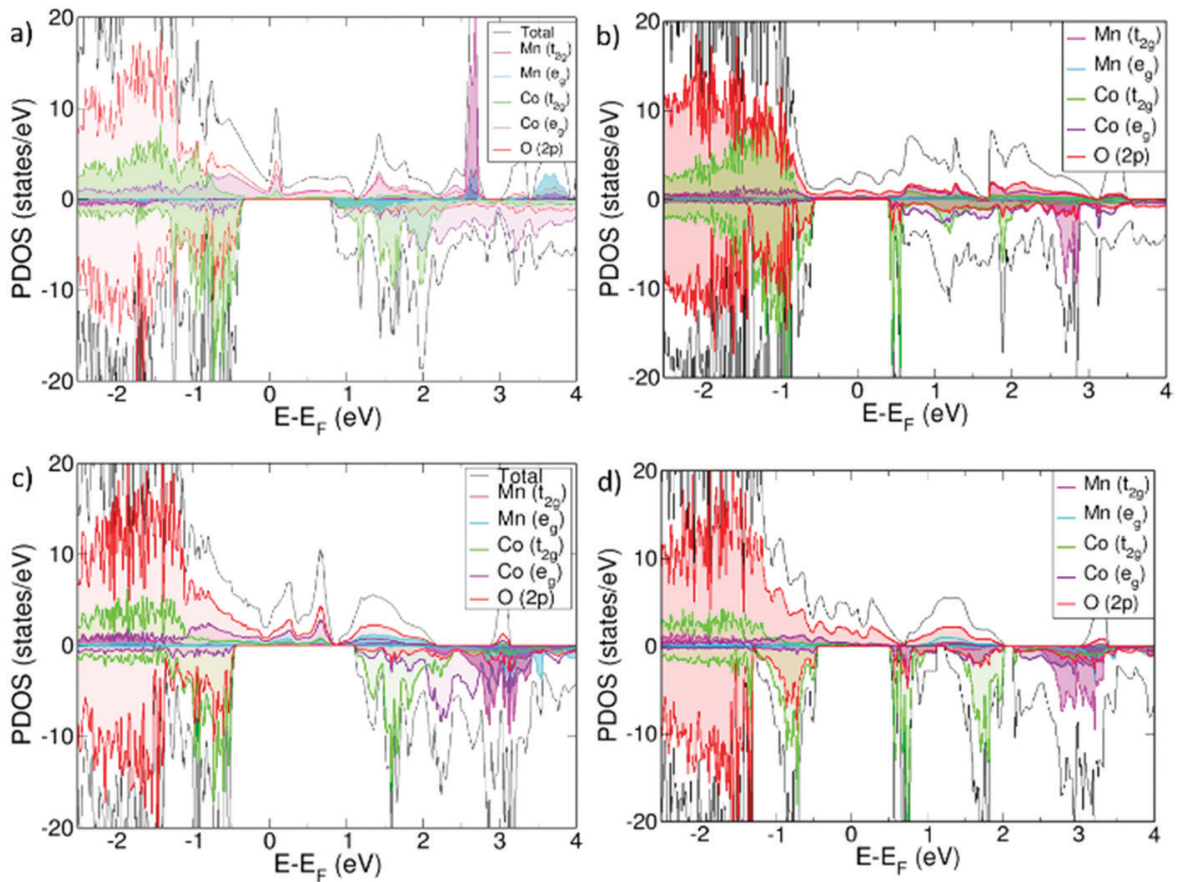

Fig. 1 Projected Density of States (PDOS) for (a) $\mathrm{Sm}_{0.75} \mathrm{Ca}_{0.25} \mathrm{Mn}_{0.125} \mathrm{Co}_{0.875} \mathrm{O}_{2.88}$, (b) $\mathrm{Sm}_{0.75} \mathrm{Sr}_{0.25} \mathrm{Mn}_{0.125} \mathrm{Co}_{0.875} \mathrm{O}_{2.88}$, (c) $\mathrm{Sm}_{0.75} \mathrm{Ca}_{0.25} \mathrm{Mn}_{0.25} \mathrm{Co}_{0.75} \mathrm{O}_{2.88}$ and (d) $\mathrm{Sm}_{0.75} \mathrm{Sr}_{0.25} \mathrm{Mn}_{0.25} \mathrm{Co}_{0.75} \mathrm{O}_{2.88}$.

$\mathrm{Ca}$ and $\mathrm{Sr}$ on the electronic structure is similar, whereas the major difference between the systems lay in the Mn concentration. For $x=0.125$ this $\alpha$-channel is mainly described by an overlapping of $\mathrm{O}(2 \mathrm{p})$ and $\mathrm{Co}_{2 \mathrm{~g}}$ and $\mathrm{e}_{\mathrm{g}}$ states, but without any contribution from the $\mathrm{Mn}(3 \mathrm{~d})$ orbitals, whereas for $x=0.25$ $\mathrm{Mn}(3 \mathrm{~d})$, both $\mathrm{t}_{2 \mathrm{~g}}$ and $\mathrm{e}_{\mathrm{g}}$ are also present. The overlap of the $t_{2 g}$ and $e_{g}$ orbitals in all electronic structures (Fig. 1), is a result of the loss of the Co octahedral environment that is necessary for an effective octahedral crystal field splitting of the orbitals, evidenced by the distortion of the $\mathrm{Co}-\mathrm{O}$ bonds relative to the non-doped SCO matrix (Table 1).

Consequently, this enables different Co d-orbital occupations from the expected $t_{2 g}^{6} e_{g}^{0}$, thus leading to low-to-intermediate spin states (LS/IS), intermediate (IS), and intermediate-to-high (IS/HS) spin states (see $\mathrm{ESI} \dagger$ for a full description of the different spin states), as deduced from Co magnetizations (Table 1).
From a non-distorted octahedral environment, cobalt magnetic moments $\left(\mu_{\mathrm{Co}}\right)$ are expected to be 0 (low spin state), but under the presence of distortions, $\mu_{\mathrm{Co}}$ increase. In the ideal case, IS gives $\mu_{\mathrm{Co}}=2$, and HS $\mu_{\mathrm{Co}}=4$, whereas the combined IS/HS will have $\mu_{\mathrm{Co}}$ with values in between 2 and 4 . For $x=0.125, \mu_{\mathrm{Co}}$ ranges from 0.19 to 2.96 for the Ca-containing system, and from 0.02-2.94 for the Sr-containing one. Hence, LS/IS, IS, and IS/HS spin states are observed for Co in both materials. For $x=0.25$, all Co in both systems show an IS state of around 2. Distortions in the Co-O bond distances, compared to pristine $\mathrm{SmCoO}_{3}$, is unequivocally related to the Co magnetic moments, where the more distorted the system is, the more uniform are $\mu_{\mathrm{Co}}$ values. Distortion, however, does not seem to influence $\mu_{\mathrm{Mn}}$ as it is high for both concentrations; the Mn-O distortions are therefore more likely to be an effect of Mn being a Jahn-Teller center. Moreover, different magnetic orderings were calculated, with

Table 1 Unique magnetic moments $(\mu)$, Bader charges $(q)$, and interatomic distances, and electronic conductivity $\left(\sigma_{\mathrm{e}}\right)$ in $\mathrm{Sm}_{0.75} \mathrm{~A}_{0.25} \mathrm{Mn}_{x} \mathrm{Co}_{1-x} \mathrm{O}_{2.88}$. Co-O distance in $\mathrm{SmCoO}_{3}$ is $1.88 \AA$. The larger $\mu_{\mathrm{Co}}$ are located closer to the oxygen vacancy, with the lowest $\mu_{\mathrm{Co}}$ being located at the furthest distance away from both the oxygen vacancy and $\mathrm{Mn}$

\begin{tabular}{lllll}
\hline & Ca & & Sr & \\
\cline { 2 - 3 } & $x=0.125$ & $x=0.25$ & $x=0.125$ & $x=0.25$ \\
\hline$\mu_{\mathrm{Mn}}\left(\mu_{\mathrm{B}}\right)$ & 3.29 & 3.48 & 3.38 & 3.49 \\
$\mu_{\mathrm{Co}}\left(\mu_{\mathrm{B}}\right)$ & $0.19,0.25,1.89,2.01,2.04,2.41,2.96$ & $2.03,2.20,2.27$ & $0.02,0.12,0.14,0.28,1.86,2.49,2.94$ & $2.31,2.32,2.92$ \\
$q_{\mathrm{A}}$ & 1.55 & 1.55 & 1.58 & 1.59 \\
$q_{\mathrm{Sm}}$ & 2.10 & 2.12 & 2.10 & 2.13 \\
$q_{\mathrm{Co}}$ & $1.23,1.25,1.31,1.34$ & $1.28,1.29,1.18,1.19$ & $1.26,1.22,1.18,1.49$ & $1.26,1.27,1.33$ \\
$q_{\mathrm{Mn}}$ & 1.71 & 1.67 & 1.77 & 1.74 \\
$q_{\mathrm{O}}$ & -1.15 & -1.16 & -1.15 & -1.18 \\
$\mathrm{Co}-\mathrm{O}(\AA)$ & $1.86,1.87,1.89,1.90,1.91$, & $1.87,1.88,1.91,1.94,1.961 .83,1.84,1.87,1.88,1.89,1.91$, & $1.85,1.86,1.88,1.89$, \\
& & $1.92,1.93,1.94,1.95,1.96,1.97$ & $1.91,1.94,1.95$ \\
$\mathrm{Mn}-\mathrm{O}(\AA)$ & $1.93,1.94,1.95,1.96,1.97$ & $1.90,1.91,1.98$ & $1.89,1.93,1.94,1.97$ & $1.91,1.93,1.94,1.95,1.97,2.00$
\end{tabular}




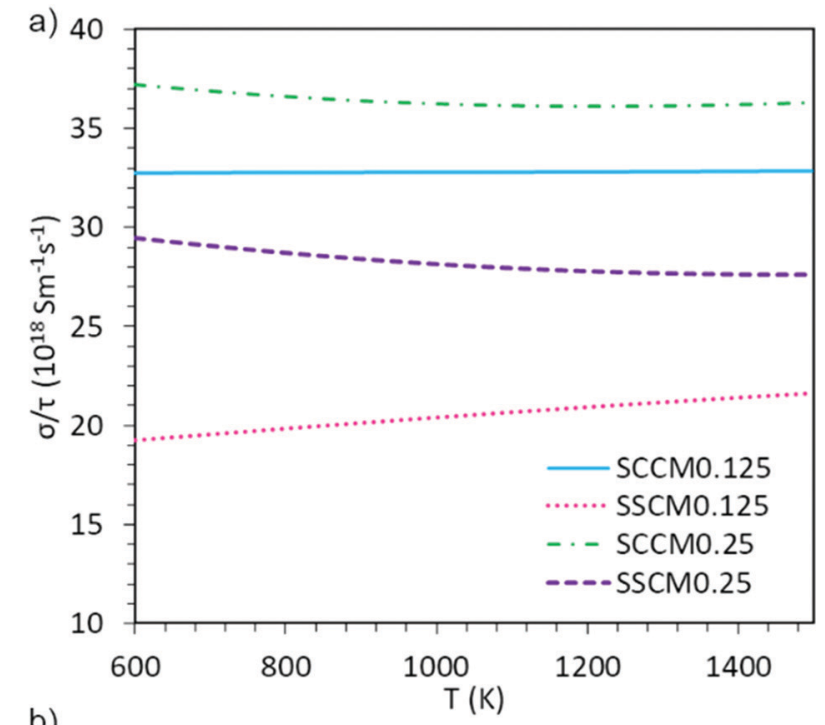

b)

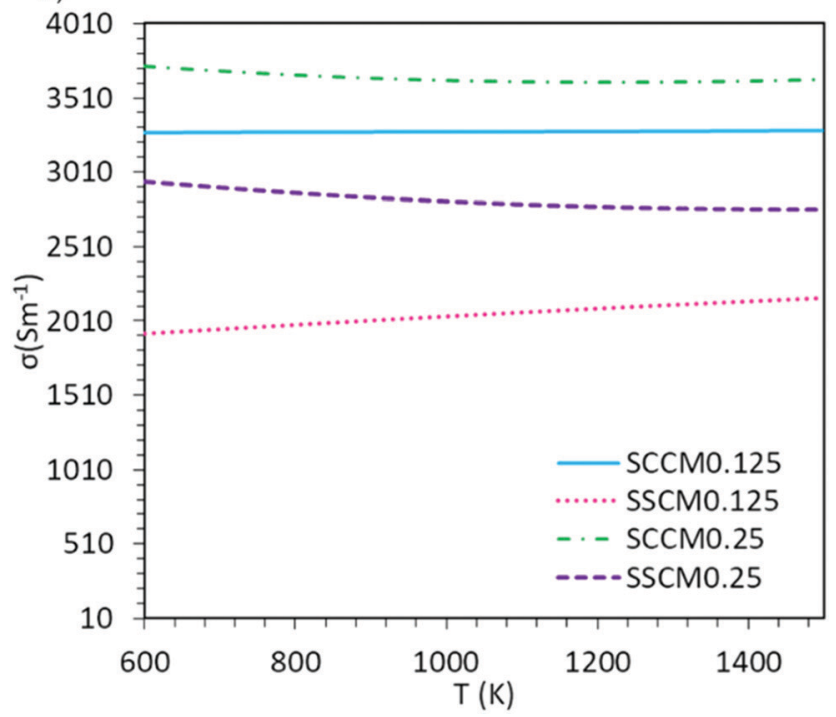

Fig. 2 The temperature dependence of the calculated (a) electrical conductivity over relaxation time, and (b) electronic conductivity assuming $\tau=10^{-16}$ s. SCCM0.125 $=\operatorname{Sm}_{0.75} \mathrm{Ca}_{0.25} \mathrm{Mn}_{0.125} \mathrm{Co}_{0.875} \mathrm{O}_{2.88}, \mathrm{SSCM} 0.125=$ $\mathrm{Sm}_{0.75} \mathrm{Sr}_{0.25} \mathrm{Mn}_{0.125} \mathrm{Co}_{0.875} \mathrm{O}_{2.88}, \mathrm{SCCM0.25}=\mathrm{Sm}_{0.75} \mathrm{Ca}_{0.25} \mathrm{Mn}_{0.25} \mathrm{Co}_{0.75} \mathrm{O}_{2.88}$ and SSCM0.25 $=\mathrm{Sm}_{0.75} \mathrm{Sr}_{0.25} \mathrm{Mn}_{0.25} \mathrm{Co}_{0.75} \mathrm{O}_{2.88}$, respectively.

the ferromagnetic found to be the most stable ordering for all cases studied. Finally, according to the calculated Bader charges, Table 1, there is no evidence of charge transfer between any of the metallic species, as was also seen in previous studies. ${ }^{13}$

\subsection{Electronic conductivity}

The subtle differences observed in the electronic structure of these materials could have a direct impact on their respective electronic transport properties, which could also vary with temperature. To evaluate the electronic transport properties of these materials at IT-SOFC conditions, the electronic conductivity as a function of temperature $(600-1500 \mathrm{~K})$ is presented in Fig. 2. It is important to note here, that due to a lack of experimental values of $\tau$ for these systems, we present both the electronic conductivity over relaxation time $\left(\sigma_{\mathrm{e}} / \tau\right)$, and $\sigma_{\mathrm{e}}$ with an approximate $\tau$ of $10^{-16} \mathrm{~s}$. $\tau$ in this range has previously been used for other cobaltate, manganate, and calcium systems. ${ }^{46-48}$ Regardless of the chosen $\tau$, these results are useful for comparing the different dopant schemes and trends therein.

The calculated $\sigma_{\mathrm{e}}$ (Fig. 2) show greater conductivity for $x=0.25$ than for $x=0.125$, indicating that a higher portion of manganese in these perovskite systems is beneficial for electronic conduction, regardless of A-site dopant. This difference in electronic conductivity between the two concentrations is directly associated with the fact that for $x=0.125$ there is no contribution from either Co or Mn at the Fermi level, whereas they do contribute for $x=0.25$, making the conduction more effective. Moreover, the Ca-containing systems show higher $\sigma_{\mathrm{e}}$, both as a function of constant relaxation time (Fig. 2a), and when explicitly setting the relaxation time (Fig. 2b). Finally, the trends regarding temperature and dopant concentration seen in Fig. 2 is in line with previous experimental results. ${ }^{5,49-53}$ At IT-SOFC operating temperatures the limiting factor to IT-SOFC cathode efficiency lies in the ionic and not the electronic conductivity, and hence it is of utmost importance that one also evaluates a material's ionic conductivity.

\subsection{Ionic conduction}

Thus, it becomes also necessary to study the ionic conductivity $\left(\sigma_{\mathrm{O}}\right)$. Computationally, $\sigma_{\mathrm{O}}$ can be calculated from oxygen diffusion coefficients $\left(D_{\mathrm{O}}\right)$, which are obtainable from the mean square displacement (MSD) of oxygen atoms, calculated using MD simulations, through

$$
\left\langle r^{2}(t)\right\rangle=6 D_{\mathrm{O}} t+B_{\mathrm{O}}
$$

where $\left\langle r^{2}(t)\right\rangle$ is the time-dependent MSD, $t$ is time, and $B_{\mathrm{O}}$ is the thermal factor associated with atomic vibrations. ${ }^{41}$ From $D_{\mathrm{O}}$, one can then calculate the oxygen migration activation energy ( $\left.E_{\text {mig }}\right)$.

$$
D_{\mathrm{O}}=D_{\text {ind }} \exp \left(\frac{-E_{\mathrm{mig}}}{k_{\mathrm{B}} T}\right)
$$

where $D_{\text {ind }}$ is the temperature-independent pre-exponential, $k_{\mathrm{B}}$ is the Boltzmann's constant, and $T$ is temperature. $E_{\text {mig }}$ can be calculated from the gradient of $\ln \left(D_{\mathrm{O}}\right)$ versus $1 / T$ Arrhenius plots. From these, $\sigma_{\mathrm{O}}$ is calculated through the Nernst-Einstein equation $^{54}$ (eqn (3)).

$$
\sigma_{\mathrm{O}}=\frac{C_{\mathrm{O}} q^{2} D_{\mathrm{O}}}{k_{\mathrm{B}} T}
$$

Here, $C_{\mathrm{O}}$ is the oxygen concentration, and $q$ the oxygen ionic charge. $D_{\mathrm{O}}$ and $E_{\mathrm{mig}}$ are presented in Table 2 along with $D_{\mathrm{O}}$ for $\mathrm{Sm}_{0.75} \mathrm{Ca}_{0.25} \mathrm{CoO}_{2.88}$ and $\mathrm{Sm}_{0.75} \mathrm{Sr}_{0.25} \mathrm{CoO}_{2.88}$ for reference.

$\mathrm{Sm}_{0.75} \mathrm{~A}_{0.25} \mathrm{Mn}_{x} \mathrm{Co}_{1-x} \mathrm{O}_{2.88}$ show very high $D_{\mathrm{O}}$ (Table 2 ), for the whole range of temperatures. As a result, oxygen diffusion is markedly more efficient in these materials than in LSM, regardless of Mn-concentration. Furthermore, $E_{\text {mig }}$ for the oxygen diffusion remains mostly unchanged with increasing $x$, at around $0.42 \mathrm{eV}$, which is $\approx 40 \%$ lower than $\mathrm{LSM}^{41}{ }^{41}$ thus confirming these materials as excellent oxygen conductors. ${ }^{54}$ Furthermore, these 
Table 2 Oxygen diffusion coefficients $\left(D_{O}\right)$ in $10^{8} \mathrm{~cm}^{2} \mathrm{~s}^{-1}$ at different temperatures, oxygen migration energy $\left(E_{\mathrm{mig}}\right)$, and thermal expansion coefficient (TEC) for $\mathrm{Sm}_{0.75} \mathrm{~A}_{0.25} \mathrm{Co}_{1-x} \mathrm{Mn}_{x} \mathrm{O}_{2.88}$

\begin{tabular}{|c|c|c|c|c|}
\hline \multirow[b]{2}{*}{$T(\mathrm{~K})$} & \multicolumn{2}{|l|}{$\underline{\mathrm{Ca}}$} & \multicolumn{2}{|l|}{$\mathrm{Sr}$} \\
\hline & $D_{\mathrm{O}}, x=0.125$ & $D_{\mathrm{O}}, x=0.25$ & $D_{\mathrm{O}}, x=0.125$ & $D_{\mathrm{O}}, x=0.25$ \\
\hline 600 & 0.759 & 2.45 & 2.17 & 2.11 \\
\hline 800 & 2.93 & 4.09 & 4.33 & 4.58 \\
\hline 1000 & 7.69 & 9.04 & 7.83 & 8.91 \\
\hline 1200 & 23.0 & 23.8 & 22.5 & 18.5 \\
\hline 1500 & 75.9 & 80.7 & 74.2 & 65.7 \\
\hline$E_{\mathrm{mig}}(\mathrm{eV})$ & 0.42 & 0.44 & 0.42 & 0.38 \\
\hline TEC $\left(\times 10^{6} \mathrm{~K}^{-1}\right)$ & 19.5 & 14.6 & 19.7 & 16.7 \\
\hline
\end{tabular}

four systems show similar $E_{\text {mig }}$ to $\mathrm{La}_{0.9} \mathrm{Sr}_{0.1} \mathrm{ScO}_{3-d}(0.47 \mathrm{eV}){ }^{55}$ Sr-doped $\quad \mathrm{LaFeO}_{3} \quad(0.44 \quad \mathrm{eV}),{ }^{16} \quad \mathrm{La}_{0.5} \mathrm{Sr}_{0.5} \mathrm{Co}_{0.75} \mathrm{Fe}_{0.25} \mathrm{O}_{3-d}$ $(0.44 \mathrm{eV}),{ }^{56} \mathrm{Ba}_{0.5} \mathrm{Sr}_{0.5} \mathrm{Co}_{0.75} \mathrm{Fe}_{0.25} \mathrm{O}_{2.88}(0.42$, and $0.46 \mathrm{eV}){ }^{57}$ and $\mathrm{Ba}_{0.5} \mathrm{Sr}_{0.5} \mathrm{CoO}_{2.88}(0.40$, and $0.43 \mathrm{eV}) .{ }^{57}$ From these results it is clear that $\mathrm{Sm}_{0.75} \mathrm{~A}_{0.25} \mathrm{Mn}_{x} \mathrm{Co}_{1-x} \mathrm{O}_{2.88}$ material presents a distinct improvement on LSM, both in terms of $E_{\text {mig }}$ and $D_{\mathrm{O}}$, and shows oxygen migration energies in line with previously reported good IT-SOFC cathode candidates. ${ }^{41}$ Additionally, from comparison with experimental LSM $\left(D_{\mathrm{O}}=3 \times 10^{-12} \mathrm{~cm}^{2} \mathrm{~s}^{-1}\right.$ at $\left.900{ }^{\circ} \mathrm{C}(1173 \mathrm{~K})^{58}\right)$, it is clear that $D_{\mathrm{O}}$ is much higher in $\mathrm{Sm}_{0.75} \mathrm{~A}_{0.25} \mathrm{Mn}_{x} \mathrm{Co}_{1-x} \mathrm{O}_{2.88}$. The calculated $\sigma_{\mathrm{O}}$ (Fig. 2), derived from $D_{\mathrm{O}}$ according to the formula shown in the ESI, $\dagger$ shows the same trend as observed for $D_{\mathrm{O}}$, with Mn-doping not providing any genuine advantage on $\sigma_{\mathrm{O}}$. However, it is clearly seen that at low temperatures, Mn-doping at $x=0.25$ is most advantageous as it produces the highest $\sigma_{\mathrm{O}}$. As the ionic conduction is the rate-limiting process (and orders of magnitudes lower than $\sigma_{\mathrm{e}}$ ) for IT-SOFC MIEC cathodes, a higher $\sigma_{\mathrm{O}}$ is more beneficial for the application investigated here. Furthermore, comparing the Sm-site dopants, $\mathrm{Sr}$ has lower $E_{\text {mig, }}$ but comparable $D_{\mathrm{O}}$ to the Ca-doped system. Hence, in agreement with studies on related lanthanide perovskites, both $\mathrm{Sr}$ and $\mathrm{Ca}$ dopants are highly beneficial for generating high oxygen ion conductivity, and more importantly higher than the traditional SOFC cathode LSM (Fig. 3)..$^{9,18,59}$

\subsection{Thermal expansion}

The suitability of these materials as IT-SOFC cathodes is further determined by their electrolyte compatibility. An IT-SOFC cathode should have a TEC of the same order as the electrolyte, too large a difference in thermal expansion responses will lead to cell failure. Hence, the final part of this study deals with the thermal expansion of $\mathrm{Sm}_{0.75} \mathrm{~A}_{0.25} \mathrm{Co}_{1-x} \mathrm{Mn}_{x} \mathrm{O}_{2.88}$. The TEC $\left(\alpha_{\mathrm{T}}\right)$ is related to the supercell volume, assuming a linear dependence, through eqn (4), and was obtained from MD simulations. ${ }^{60}$

$$
\alpha_{\mathrm{T}}=\frac{1}{V_{0}} \frac{\mathrm{d} V}{\mathrm{~d} T}
$$

$V$ is the lattice volume, and $V_{0}$ is the reference lattice volume.

For $\mathrm{Sm}_{0.75} \mathrm{~A}_{0.25} \mathrm{Co}_{1-x} \mathrm{Mn}_{x} \mathrm{O}_{2.88}$ to be a viable candidate material for SOFC cathodes, its TEC needs to be close to that of SOFC electrolyte materials. Common SOFC electrolytes include YSZ, LSGM, and GDC, which have TEC of $10-13 \times 10^{-6} \mathrm{~K}^{-1}$, and it is generally accepted that cathodes with TEC smaller than $15 \times 10^{-6} \mathrm{~K}^{-1}$ are suitable. ${ }^{61,62}$ TEC for $x=0.125$ is calculated to be $19.5 \times 10^{-6} \mathrm{~K}^{-1}$, and $19.7 \times 10^{-6} \mathrm{~K}^{-1}$ for Ca- and Sr-doped, respectively. A larger difference in the thermal expansion behavior is observed at $x=0.25$, where Ca-doped has a TEC of $14.6 \times 10^{-6} \mathrm{~K}^{-1}$, and Sr-doped $16.7 \times 10^{-6} \mathrm{~K}^{-1}$, which shows that these materials should be suitable for IT-SOFC cathodes.

\section{Conclusion}

In this work, a systematic DFT and MD study of $\mathrm{Sm}_{0.75} \mathrm{~A}_{0.25^{-}}$ $\mathrm{Co}_{1-x} \mathrm{Mn}_{x} \mathrm{O}_{2.88}$ has been conducted to elucidate these materials' suitability as next-generation IT-SOFC cathodes. $\mathrm{Sm}_{0.75} \mathrm{Ca}_{0.25^{-}}$ $\mathrm{Co}_{0.75} \mathrm{Mn}_{0.25} \mathrm{O}_{2.88}$ showed the most promising electronic conductivity occurring via both Co and Mn d-orbitals that overlap at the Fermi level. This overlap is a consequence of the distortion induced by the dopants, which at the same time facilitates a different electron occupation in the metal-d orbitals, which overall results in a ferromagnetic arrangement of the different magnetic moments. Improvement, as compared to $\mathrm{SmCoO}_{3}$ and
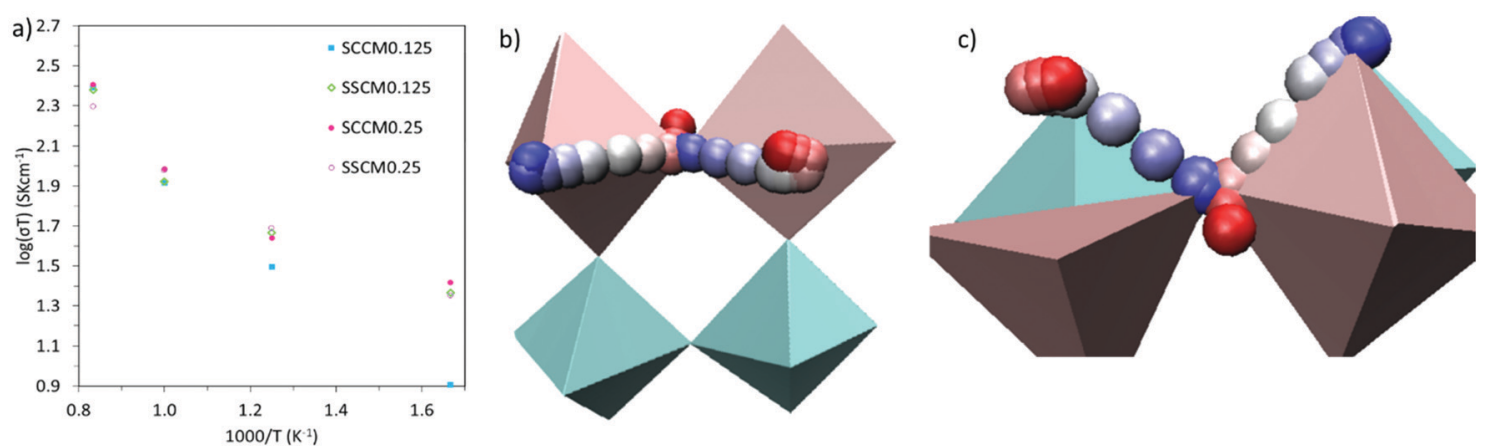

Fig. 3 (a) Log-plot of ionic conductivity versus 1000/T. SCCM0.125 $=\mathrm{Sm}_{0.75} \mathrm{Ca}_{0.25} \mathrm{Mn}_{0.125} \mathrm{Co}_{0.875} \mathrm{O}_{2.88}, \mathrm{SSCMO}_{125}=\mathrm{Sm}_{0.75} \mathrm{Sr}_{0.25} \mathrm{Mn}_{0.125} \mathrm{Co}_{0.875} \mathrm{O}_{2.88}$, SCCM0.25 $=\mathrm{Sm}_{0.75} \mathrm{Ca}_{0.25} \mathrm{Mn}_{0.25} \mathrm{Co}_{0.75} \mathrm{O}_{2.88}$, and SSCM0.25 $=\mathrm{Sm}_{0.75} \mathrm{Sr}_{0.25} \mathrm{Mn}_{0.25} \mathrm{Co}_{0.75} \mathrm{O}_{2.88}$, respectively. A schematic of a typical oxygen migration path following an oxygen-vacancy hopping mechanism is shown in (b) as a side view and in (c) as a top view (with the oxygen vacancy seen from the unfilled pink polyhedra). For both (b) and (c), Co is located in the centre of the light blue polyhedra, and Mn in the centre of the pink polyhedra. The migrating oxygen atom is presented at different paths of its trajectory in terms of red, blue and white spheres. The white spheres represents the transition or intermediate states, whereas the blue and red spheres shows oxygen start and final states, which are the lowest energy states. 
LSM, was also observed in the ionic conduction, which is the limiting factor for the efficiency of the material at operating temperatures. In fact, $\mathrm{Sm}_{0.75} \mathrm{Ca}_{0.25} \mathrm{Mn}_{x} \mathrm{Co}_{1-x} \mathrm{O}_{2.88}$ has much higher ionic conductivity and a lower activation energy for oxygen migration than LSM, with fast oxygen diffusion even at lower temperatures. Finally, the last bit of the IT-SOFC cathode puzzle is the mechanical coupling between electrolyte and cathode, described in terms of TEC. We show here, that introducing manganese into the lattice, at $x=0.25$, dramatically decreases TEC, reducing it to a value close to IT-SOFC electrolytes. Comparing in between the Sm-site dopants, Ca doping gives slightly lower TEC than $\mathrm{Sr}$, in conjunction with previous studies. The combination of all these properties suggests that $\mathrm{Sm}_{0.75} \mathrm{~A}_{0.25} \mathrm{Mn}_{0.25} \mathrm{Co}_{0.75} \mathrm{O}_{2.88}$ would combine the optimum bulk properties desirable for IT-SOFC cathode material. These results further justify an investigation into the surface properties of this material, especially into the oxygen reduction reaction kinetics, and will be the topic of a future report.

\section{Conflicts of interest}

The authors declare no competing interests.

\section{Acknowledgements}

The authors acknowledge the Engineering and Physical Sciences Research Council (EPSRC) for financial support (Grants references EP/K016288/1 and EP/K001329/1), the UCL Grace High Performance Computing Facility (Grace@UCL), and the Hartree Centre resources in this work. Finally, via our membership of the UK's HPC Materials Chemistry Consortium, which is funded by EPSRC (EP/L000202, EP/R029431), this work made use of the facilities of ARCHER, the UK's national high-performance computing service. N. H. D. L. thanks the Royal Society for an Industry Fellowship. E. O. gratefully acknowledges EPSRC funding from the Centre for Doctoral Training in Molecular Modelling and Materials Science (EP/G036675/1). Information on the data underpinning the results presented here, including how to access them, can be found in the Cardiff University data catalogue at http://doi.org/ 10.17035/d.2019.0086840493.

\section{References}

1 I. Fullarton, J. Jacobs and H. Van Benthem, Study of oxygen ion transport in acceptor doped samarium cobalt oxide, Ionics, 1995, 1, 51-58.

2 R. M. Ormerod, Solid oxide fuel cells, Chem. Soc. Rev., 2003, 32, 17-28.

3 B. C. Steele and A. Heinzel, Materials for fuel-cell technologies, Nature, 2001, 414, 345-352.

4 C. Yu and S. B. Adler, Thermal and Chemical Expansion of Sr-Doped Lanthanum Cobalt Oxide $\left(\mathrm{La}_{1-x} \mathrm{Sr}_{x} \mathrm{CoO}_{3-\delta}\right)$, Chem. Mater., 2005, 17, 4537-4546.

5 Y. Wang, X. Zhao, S. Lü, X. Meng, Y. Zhang, B. Yu, X. Li, Y. Sui, J. Yang, C. Fu and Y. Ji, Synthesis and characterization of $\mathrm{SmSrCo}_{2-x} \mathrm{Mn}_{x} \mathrm{O}_{5+\delta}(x=0.0,0.2,0.4,0.6,0.8,1.0)$ cathode materials for intermediate-temperature solid-oxide fuel cells, Ceram. Int., 2014, 40, 11343-11350.

6 S. M. Haile, Fuel cell materials and components. The Golden Jubilee Issue-Selected topics in Materials Science and Engineering: Past, Present and Future, Acta Mater., ed. S. Suresh, 2003, vol. 51, pp. 5981-6000.

7 S. J. Skinner, Recent advances in Perovskite-type materials for solid oxide fuel cell cathodes, Int. J. Inorg. Mater., 2001, 3, 113-121.

8 J. Van Herle, A. J. J. McEvoy and K. Ravindranathan Thampi, A study on the $\mathrm{La}_{1-x} \mathrm{Sr}_{x} \mathrm{MnO}_{3}$ oxygen cathode, Electrochim. Acta, 1996, 41, 1447-1454.

9 R. A. De Souza, J. A. Kilner and J. F. Walker, A SIMS study of oxygen tracer diffusion and surface exchange in $\mathrm{La}_{0.8} \mathrm{Sr}_{0.2^{-}}$ $\mathrm{MnO}_{3+\delta}$, Mater. Lett., 2000, 43, 43-52.

10 R. Pelosato, G. Cordaro, D. Stucchi, C. Cristiani and G. Dotelli, Cobalt based layered perovskites as cathode material for intermediate temperature Solid Oxide Fuel Cells: A brief review, J. Power Sources, 2015, 298, 46-67.

11 Y. Cao, M. J. Gadre, A. T. Ngo, S. B. Adler and D. D. Morgan, Factors controlling surface oxygen exchange in oxides, Nat. Commun., 2019, 10, 1346.

12 E. Olsson, X. Aparicio-Anglès and N. H. de Leeuw, A computational study of the electronic properties, ionic conduction, and thermal expansion of $\mathrm{Sm}_{1-x} \mathrm{~A}_{x} \mathrm{CoO}_{3}$ and $\mathrm{Sm}_{1-x} \mathrm{~A}_{x} \mathrm{CoO}_{3-x / 2}\left(\mathrm{~A}=\mathrm{Ba}^{2+}, \mathrm{Ca}^{2+}, \mathrm{Sr}^{2+}\right.$, and $\left.x=0.25,0.5\right)$ as intermediate temperature SOFC cathodes, Phys. Chem. Chem. Phys., 2017, 19, 13960-13969.

13 E. Olsson, J. Cottom, X. Aparicio-Anglès and N. H. de Leeuw, Computational study of the mixed B-site perovskite $\mathrm{SmB}_{x} \mathrm{Co}_{1-x} \mathrm{O}_{3-\mathrm{d}}(\mathrm{B}=\mathrm{Mn}, \mathrm{Fe}, \mathrm{Ni}, \mathrm{Cu})$ for next generation solid oxide fuel cell cathodes, Phys. Chem. Chem. Phys., 2019, 21, 9407-9418.

14 M. S. Islam, P. R. Slater, J. R. Tolchard and T. Dinges, Doping and defect association in $\operatorname{AZrO}(3)(\mathrm{A}=\mathrm{Ca}, \mathrm{Ba})$ and $\operatorname{LaMO}(3)(\mathrm{M}=\mathrm{Sc}, \mathrm{Ga})$ perovskite-type ionic conductors, Dalton Trans., 2004, 3061-3066.

15 J. Okasinski, J. B. Cohen, J. Hwang, T. O. Mason, Z. Ding, O. Warschkow and D. E. Ellis, Defect and electronic structures of calcium-doped lanthanum cuprate, J. Am. Ceram. Soc., 1999, 82, 2451-2459.

16 A. Jones and M. S. Islam, Atomic-scale insight into $\mathrm{LaFeO}_{3}$ perovskite: Defect nanoclusters and ion migration, J. Phys. Chem. C, 2008, 112, 4455-4462.

17 M. S. Islam, Computer modelling of defects and transport in perovskite oxides, Solid State Ionics, 2002, 154-155, 75-85.

$18 \mathrm{M}$. Islam and M. Cherry, Protons in $\mathrm{LaMO}_{3}$ : atomistic modelling and ab initio studies, Solid State Ionics, 1997, 97, 33-37.

19 M. S. D. Read, M. S. Islam, G. W. Watson, F. King and F. E. Hancock, Defect chemistry and surface properties of $\mathrm{LaCoO}_{3}$, J. Mater. Chem., 2000, 10, 2298-2305.

20 G. Kresse and J. Hafner, Ab initio molecular dynamics for liquid metals, Phys. Rev. B: Condens. Matter Mater. Phys., 1993, 47, 558. 
21 G. Kresse and J. Hafner, Ab initio molecular-dynamics simulation of the liquid-metal-amorphous-semiconductor transition in germanium, Phys. Rev. B: Condens. Matter Mater. Phys., 1994, 49, 14251.

22 G. Kresse and J. Furthmüller, Efficiency of ab-initio total energy calculations for metals and semiconductors using a plane-wave basis set, Comput. Mater. Sci., 1996, 6, 15-50.

23 G. Kresse and J. Furthmüller, Efficient iterative schemes for ab initio total-energy calculations using a plane-wave basis set, Phys. Rev. B: Condens. Matter Mater. Phys., 1996, 54, 11169-11186.

24 P. E. Blöchl, Projector augmented-wave method, Phys. Rev. B: Condens. Matter Mater. Phys., 1994, 50, 17953.

25 J. Perdew, K. Burke and M. Ernzerhof, Errata: Generalized Gradient Approximation Made Simple, Phys. Rev. Lett., 1997, 77, 1396.

26 P. E. Blöchl, O. Jepsen and O. K. Andersen, Improved tetrahedron method for Brillouin-zone integrations, Phys. Rev. B: Condens. Matter Mater. Phys., 1994, 49, 16223-16233.

27 H. J. Monkhorst and J. D. Pack, Special points for Brillouinzone integrations, Phys. Rev. B: Solid State, 1976, 13, 5188-5192.

28 R. F. W. Bader, Atoms in Molecules: A Quantum Theory, Oxford University Press, Oxford, 1990.

29 G. Henkelman, A. Arnaldsson and H. Jónsson, A fast and robust algorithm for Bader decomposition of charge density, Comput. Mater. Sci., 2006, 36, 354-360.

30 T. Geng, Z. Han and S. Zhuang, Effective Coulomb interaction in $\mathrm{LaMnO}_{3}$, Phys. B, 2010, 405, 3714-3716.

31 P. Ravindran, A. Kjekshus, H. Fjellvåg, A. Delin and O. Eriksson, Ground-state and excited-state properties of $\mathrm{LaMnO}_{3}$ from full-potential calculations, Phys. Rev. B: Condens. Matter Mater. Phys., 2002, 65, 064445.

32 P. Ravindran, R. Vidya, H. Fjellvåg and A. Kjekshus, Electronic Structure and Excited-state Properties of Perovskite-like Oxides, J. Cryst. Growth, 2004, 268, 554-559.

33 S. Dudarev, G. Botton and S. Savrasov, Electron-energy-loss spectra and the structural stability of nickel oxide: An LSDA+U study, Phys. Rev. B: Condens. Matter Mater. Phys., 1998, 57, 1505-1509.

34 Y.-L. Lee, J. Kleis, J. Rossmeisl and D. Morgan, Ab initio energetics of $\mathrm{LaBO}_{3}$ (001) (B = Mn, Fe, Co, and Ni) for solid oxide fuel cell cathodes, Phys. Rev. B: Condens. Matter Mater. Phys., 2009, 80, 224101.

35 E. Olsson, X. Aparicio-Anglès and N. H. de Leeuw, Ab initio study of vacancy formation in cubic $\mathrm{LaMnO}_{3}$ and $\mathrm{SmCoO}_{3}$ as cathode materials in solid oxide fuel cells, J. Chem. Phys., 2016, 145, 014703.

36 G. K. H. Madsen and D. J. Singh, BoltzTraP. A code for calculating band-structure dependent quantities, Comput. Phys. Commun., 2006, 175, 67-71.

37 I. T. Todorov, W. Smith, K. Trachenko and M. T. Dove, DL_POLY, J. Mater. Chem., 2006, 16, 1911-1918.

38 W. G. Hoover, Canonical dynamics: Equilibrium phasespace distributions, Phys. Rev. A: At., Mol., Opt. Phys., 1985, 31, 1695-1697.

39 M. Born and J. Mayer, Lattice theory of ionic solids, Phys. B, 1932, 75, 1-18.
40 J. E. Mayer, Dispersion and Polarizability and the van der Waals Potential in the Alkali Halides, J. Chem. Phys., 1933, 1, 270-279.

41 M. S. Islam, M. Cherry and C. R. A. Catlow, Oxygen Diffusion in $\mathrm{LaMnO}_{3}$ and $\mathrm{LaCoO}_{3}$ Perovskite-Type Oxides: A Molecular Dynamics Study, J. Solid State Chem., 1996, 124, 230-237.

42 M. Cherry, M. S. Islam and C. R. A. Catlow, Oxygen ion migration in perovskite-type oxides, J. Solid State Chem., 1995, 118, 125-132.

43 T. S. Bush, J. D. Gale, C. R. A. Catlow and P. D. Battle, Selfconsistent interatomic potentials for the simulation of binary and ternary oxides, J. Mater. Chem., 1994, 4, 831.

44 G. V. Lewis and C. R. A. Catlow, Potential models for ionic oxides, J. Phys. C: Solid State Phys., 1985, 18, 1149-1161.

45 R. Grau-Crespo, S. Hamad, C. R. A. Catlow and N. H. de Leeuw, Symmetry-adapted configurational modelling of fractional site occupancy in solids, J. Phys.: Condens. Matter, 2007, 19, 256201.

46 J. D. Baran, M. Molinari, N. Kulwongwit, F. Azough, R. Freer, D. Kepaptsoglou, Q. M. Ramasse and S. C. Parker, Tuning Thermoelectric Properties of Misfit Layered Cobaltites by Chemically Induced Strain, J. Phys. Chem. C, 2015, 119, 21818-21827.

47 M. Molinari, D. a. Tompsett, S. C. Parker, F. Azough and R. Freer, Structural, electronic and thermoelectric behaviour of $\mathrm{CaMnO}_{3}$ and $\mathrm{CaMnO}_{(3-\delta)}$, J. Mater. Chem. A, 2014, 2, 14109.

48 J. D. Baran, C. Eames, K. Takahashi, M. Molinari, M. S. Islam and S. C. Parker, Structural, Electronic, and Transport Properties of Hybrid $\mathrm{SrTiO}_{3}$-Graphene and Carbon Nanoribbon Interfaces, Chem. Mater., 2017, 29, 7364-7370.

49 H. Kozuka, K. Ohbayashi and K. Koumoto, $\mathrm{LaCo}_{1-x} \mathrm{Ni}_{x} \mathrm{O}_{3}$ with Improved Electrical Conductivity, Inorg. Chem., 2012, 51, 9259-9264.

50 H. Kozuka, H. Yamada, T. Hishida, K. Ohbayashi and K. Koumoto, $\mathrm{Sr}_{x} \mathrm{La}_{1-x} \mathrm{MnO}_{3}$ : N-type oxides with phase stability at high temperatures in air, J. Mater. Chem. A, 2013, 1, 3249-3253.

51 H. Kozuka, K. Ohbayashi and K. Koumoto, Electronic conduction in La-based perovskite-type oxides, Sci. Technol. Adv. Mater., 2015, 16, 026001.

52 H. Kozuka, H. Yamada, T. Hishida, K. Yamagiwa, K. Ohbayashi and K. Koumoto, Electronic transport properties of the perovskite-type oxides $\mathrm{La}_{1-x} \mathrm{Sr}_{x} \mathrm{CoO}_{3} \pm$ delta, J. Mater. Chem., 2012, 22, 20217.

53 K. Cvejin, L. Manjakkal, J. Kulawik, K. Zaraska and D. Szwagierczak, Characterization and applicability of $\mathrm{Sm}_{0.9} \mathrm{Sr}_{0.1} \mathrm{CoO}_{3-\delta}$ in oxygen sensors, Microelectron. Int., 2014, 31, 154-157.

54 T. C. Yeh, J. L. Routbort and T. O. Mason, Oxygen transport and surface exchange properties of $\mathrm{Sr}_{0.5} \mathrm{Sm}_{0.5} \mathrm{CoO}_{3-\delta}$, Solid State Ionics, 2013, 232, 138-143.

55 T. T. Mayeshiba and D. D. Morgan, Factors controlling oxygen migration barriers in perovskites, Solid State Ionics, 2016, 296, 71-77. 
56 Y. A. Mastrikov, R. Merkle, E. A. Kotomin, M. M. Kuklja and J. Maier, Formation and migration of oxygen vacancies in $\mathrm{La}_{(1-x)} \mathrm{Sr}_{(x)} \mathrm{Co}_{(1-y)} \mathrm{Fe}_{(y)} \mathrm{O}_{(3-\delta)}$ perovskites: insight from ab initio calculations and comparison with $\mathrm{Ba}_{(1-x)} \operatorname{Sr}_{(x)} \mathrm{Co}_{(1-y)} \mathrm{Fe}_{(y)} \mathrm{O}_{(3-\delta)}$, Phys. Chem. Chem. Phys., 2013, 15, 911-918.

57 M. M. Kuklja, E. A. Kotomin, R. Merkle, Y. A. Mastrikov and J. Maier, Combined theoretical and experimental analysis of processes determining cathode performance in solid oxide fuel cells, Phys. Chem. Chem. Phys., 2013, 15, 5443-5471.

58 S. P. Jiang, Development of lanthanum strontium manganite perovskite cathode materials of solid oxide fuel cells: a review, J. Mater. Sci., 2008, 43, 6799-6833.

59 C. Tealdi, L. Malavasi, C. A. J. Fisher and M. S. Islam, Disproportionation, dopant incorporation, and defect clustering in perovskite-structured $\mathrm{NdCoO}_{3}$, J. Phys. Chem. B, 2006, 110, 5395-5402.

60 N. Orlovskaya, M. Lugovy, S. Pathak, D. Steinmetz, J. Lloyd, L. Fegely, M. Radovic, E. A. Payzant, E. Lara-curzio, L. F. Allard and J. Kuebler, Thermal and mechanical properties of $\mathrm{LaCoO}_{3}$ and $\mathrm{La}_{0.8} \mathrm{Ca}_{0.2} \mathrm{CoO}_{3}$ perovskites, J. Power Sources, 2008, 182, 230-239.

61 Z. Gao, L. V. Mogni, E. C. Miller, G. Railsback, S. A. Barnett, J. G. Railsback and S. A. Barnett, A perspective on lowtemperature solid oxide fuel cells, Energy Environ. Sci., 2016, 9, 1602-1644.

$62 \mathrm{~J}$. A. Kilner and M. Burriel, Materials for IntermediateTemperature Solid-Oxide Fuel Cells, Annu. Rev. Mater. Res., 2014, 44, 365-393. 